\title{
Aquifer response to recharge-discharge phenomenon: inference from well hydrographs for genetic classification
}

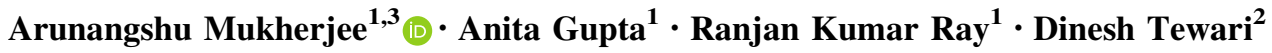

Received: 18 July 2014/ Accepted: 4 May 2015 / Published online: 26 May 2015

(c) The Author(s) 2015. This article is published with open access at Springerlink.com

\begin{abstract}
The continuous groundwater level data emanating from a high-frequency automatic water level recorder installed in a purpose-built piezometer provides a true hydrograph. Analyses of such hydrographs fairly reflect the aquifer character and can be used to draw inference for genetic classification of hard rock aquifers. The signature shape of annual water level fluctuation curve (annual cycle) of a piezometer is due to the specific character of the aquifer and the way it responds to the rechargedischarge phenomenon. The pattern of annual cycle remains identical year after year, although its magnitude may vary with the annual quantum of recharge-discharge. Lithology of the aquifer does not control the shape of the curve. Based on the crest and trough shape, the hard rock aquifers of Peninsular India, where the monsoonal pattern of rainfall occurs, have been classified into genetic groups. It is also found that the nature of the aquifer can be determined by visual comparison of apparent line thickness of the hydrograph, where thin lines denote unconfined aquifer and the apparently thicker lines correspond to confining condition. The response of an aquifer to a pumping event can be identified and separated by its pattern. Thus, the aquifer classification can be automated by adopting the proposed classification scheme.
\end{abstract}

Electronic supplementary material The online version of this article (doi:10.1007/s13201-015-0293-z) contains supplementary material, which is available to authorized users.

Arunangshu Mukherjee

arunmuk102@gmail.com

Central Ground Water Board, RGI, Faridabad 121001, India

2 Central Ground Water Board, Chandigarh 160019, India

3 Present Address: Upper Yamuna River Board, R K Puram, New Delhi 110066, India
Keywords Well hydrograph - Piezometer - Aquifer response - Genetic classification · Peninsular India

\section{Introduction}

The complex behavior of a hard rock aquifer is well appreciated (Singhal 2007) and its knowledge is under constant evolution. Peninsular India ( $>1.7$ million $\mathrm{km}^{2}$ area of central and southern parts of India) is home to hard rocks of Indian shield and Deccan basalt, consisting largely of crystalline, metamorphic and consolidated sedimentary rocks (Fig. 1). The study of aquifer character within this vast terrain may help in better understanding of hard rock hydraulics. The well productivity (available discharge per well) is dependent on the physical parameters of an aquifer such as porosity, permeability, storativity, confining status, recharge, flow, etc., which also define the aquifer characteristics. The aquifer character, in turn, is responsible for the aquifer's response to recharge-discharge phenomenon, which can be interpreted by recording the water level fluctuations, using a high frequency water level recorder fitted in a purpose-built piezometer, in the form of a time series data "hydrograph" (the variation in groundwater level recorded systematically for a longer period can be plotted in the form of a graph called hydrograph). Analyses of such continuous hydrographs fairly reflect the aquifer character and can be used to draw inference for aquifers genetic classification. The analysis indicates that the time series data of groundwater levels are cyclical with characteristics of seasonal variation (Thakur and Thomas 2011). Well hydrographs were also used for estimation of other parameters as aquifer recharge (Raj 2004; Kumar 2010), tidal and barometric efficiency (Maréchal et al. 2010) etc. A recession predominantly results from natural 
Fig. 1 Location of study area within India and its geology. Note the distribution of hard rocks $(2 \& 3)$ in Peninsular India

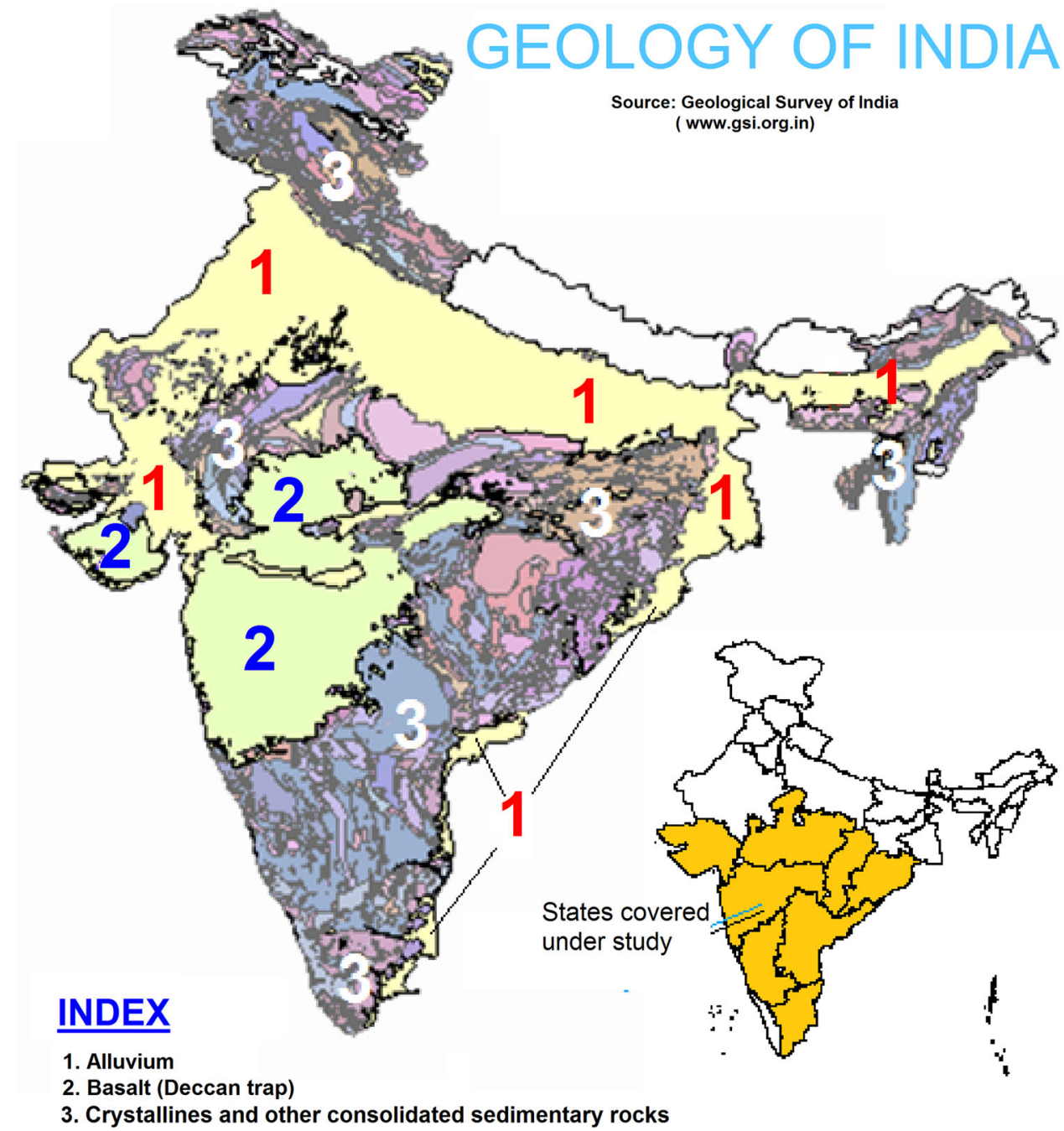

drainage and is related to the aquifer geometry and the diffusivity $(T / S)$. Thus, an analysis of such a recession can provide a preliminary estimate of the diffusivity, which in turn may lead to an estimation of transmissivity $(T)$ or the storage coefficient $(S)$, knowing the other (Hydrology Project 2000). The groundwater fluctuations are a result of aquifer response and depend on (i) aquifer character (ii) type of recharge or discharge phenomenon and its duration or combination of these. These fluctuations generated for an adequate regular interval when analyzed (Harmonic analysis; Hydrology Project 2000) for a reasonably long period may show a varied cycle, for instance hourly cycle, six hourly cycle, daily cycle, fortnightly cycle, monthly cycle or annual cycle, etc. The annual cycle is the most dominant cycle in India, where rainfall is monsoonal in pattern (clear wet and dry season). Further, some other pattern can also be identified from the plot of time series data for a particular piezometer when collected for a long period, which can generally be considered as a representative of a particular aquifer or an area.
In the present paper, an attempt has been made for the first time using an exhaustive database to classify the hard rock aquifers of Peninsular India based on their response to recharge-discharge phenomenon recorded in the form of a hydrograph. The main objective of the study is to (i) identify the regular patterns of response of aquifer, if any (ii) interpret the characteristic behaviour responsible for such a regular patterns of response of aquifer and (iii) classify the hard rock aquifer based on similarities of aquifer response.

\section{Methodology}

Under World Bank assisted Hydrology Project (Phase-I) purpose-built piezometers were drilled by the Central Ground Water Board (CGWB) in hard rock terrain of the Peninsular India to depths of 30,60, and $90 \mathrm{~m}$. The depth range selected was to tap weathered zone or shallow fracture/fracture zone down to $30 \mathrm{~m}$, between 30 and $60 \mathrm{~m}$ 


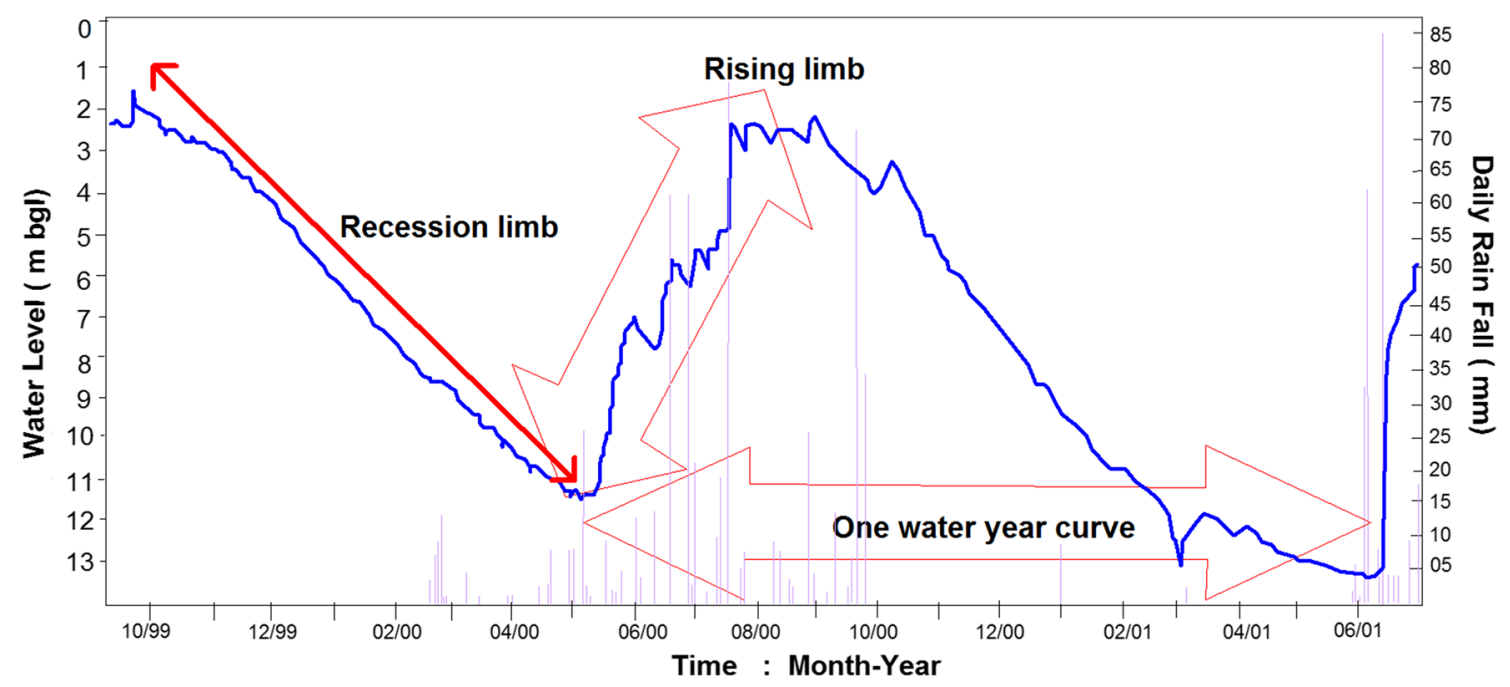

Fig. 2 A typical true hydrograph generated from data collected by an automatic water level recorder fitted in a well (piezometer). Note the daily rainfall hyetograph and corresponding rise in water level during monsoon period. Location: Raipur

and in the range of 60-90 $\mathrm{m}$ depth separately. Groundwater level data and well information were collected. Many of these wells were fitted with a pressure transducer type high frequency digital automatic water level recorder (DWLR) scheduled to record six hourly data to obtain a continuous groundwater level spectrum. Further, these DWLRs also had the capability to automatically record any extreme event (anomalous rise or fall) that may occur intermittently in groundwater levels outside of defined interval. The data so obtained from each piezometer was downloaded onto a computer. Dedicated software "GEMS" ("Groundwater Estimation and Management software" developed by CGWB) was used to store and retrieve these data along with its well information and to generate a hydrograph for a requisite period from all over the country. This was to ensure measurement of the undistorted piezometric head at the desired frequency, which was larger than the traditional frequency. In fact, the frequency is so high that the resulting piezometric hydrograph may almost be continuous. The GEMS can also incorporate corresponding daily rainfall of the piezometer site. More than 250 representative true hydrographs so obtained in uniform format, having time series data of more than one annual cycle, were compared and analyzed. Selected hydrograph were from hard rock area of eight Indian States namely Andhra Pradesh, Chhattisgarh, Gujarat, Karnataka, Maharashtra, Madhya Pradesh, Orissa and Tamilnadu (Fig. 1). Based on identified marked similarities in the crest and trough shape of true hydrographs and by comparison of apparent line thickness of curves representing different litho-type which were spatially distributed over about 1.7 million $\mathrm{km}^{2}$ area, the hard rock aquifers of the Peninsular India have been classified into genetic groups.

\section{Results}

The hydrograph obtained through DWLR data are designated as true hydrograph (Hydrology Project 2000) and are quite different from those obtained traditionally through manual measurements of groundwater level, where the frequency is generally either monthly/quarterly or at the most daily. As stated earlier the Peninsular States in India (study area) are characterized by a well-defined rainy season "monsoon" (June-September). Largely the rainfall occurs (nearly $90 \%$ ) during this period, thus the area having clear-cut annual wet and dry season. This is reflected in the hydrographs as well in the form of two welldefined limbs (Fig. 2). Thus the two limbs of hydrograph generated due to the seasonal groundwater level fluctuation are product of (a) response to the recharge phenomenon i.e. formation of rising limb or crest/peaks and (b) response to the discharge phenomenon i.e. formation of recession limb or trough. The true hydrographs obtained from the Peninsular India can be visually compared and classified into groups of identical classes.

The shape of the annual hydrograph for a particular well remains nearly identical in subsequent years in spite of changes in its magnitude due to variation in annual recharge/ discharge to/from the aquifer. Based on recharge pulses and its capacity, the magnitude of the response curve or a segment of the hydrograph can vary, but due to the characteristic aquifer response of each site the overall shape of annual recharge-discharge hydrograph of subsequent years largely remains same and can be virtually superimposed on each other up to a great extent (Fig. 3). This clearly establishes that the overall shape of recharge-discharge curve or true hydrograph of a well is primarily controlled by the aquifer 

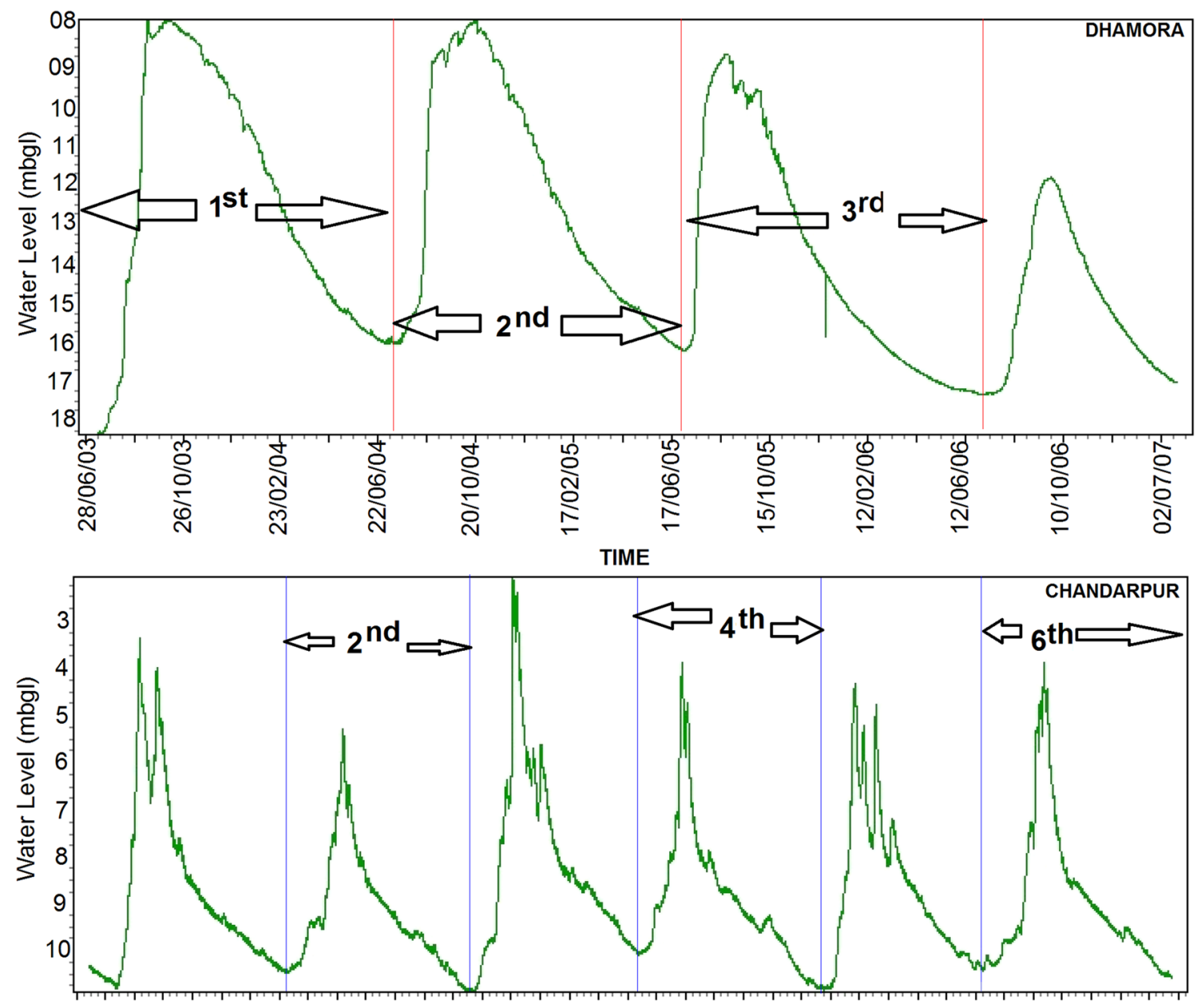

Fig. 3 Identical annual curves of true hydrograph of successive years from two locations

response, which in turn depends on aquifer properties. This can be also seen in Figs. 4, 5, 6, 7.

\section{Recharge phenomenon}

In response to monsoon recharge groundwater level rises to its shallowest level, generating the rising limb. Based on the rainfall pattern and amount during monsoon, the peak takes its shape as per the aquifer character.

\section{Shape of crest}

1. Hydrograph crests from study area can be described as pointed, flat or rounded in shape. The order of abundance of crest shape in the Peninsular hard rocks is pointed $>$ flat $>$ rounded (Fig. 4).

2. The crest shapes are characteristic and do not change for a particular well/piezometer, however the magnitude or width may vary annually. This reflects the aquifer character control over the crest shape, whereas its magnitude and width is controlled by the quantum of recharge. For example flat top crest remains flat top whatever is the magnitude and so on.

3. Pointed crests are either single peak or multi peaked. The number of peak/peaks and its width varies annually based on rainfall pattern and quantity.

Thus, each well/piezometer has a signature curve pattern. The signature pattern of individual piezometer reflects heterogeneity of the aquifer. However, the curves can be classified into groups based on gross similarity.

\section{Discharge phenomenon}

In response to the base flow and or the draft, the water level starts declining after the monsoon thus generating the recession limb. The combination of rising and recession limb pattern can be classified into three types, viz. (a) V type curve (b) U type curve and (c) S type curve.

1. V type curves are those curves where both rising and recession limbs have nearly same slope angle though the rising limbs may sometimes be steeper then 
Fig. 4 Type of crest of true hydrograph. Note the consistent shape of crest in subsequent annual cycle in the hydrograph
Pointed Crest
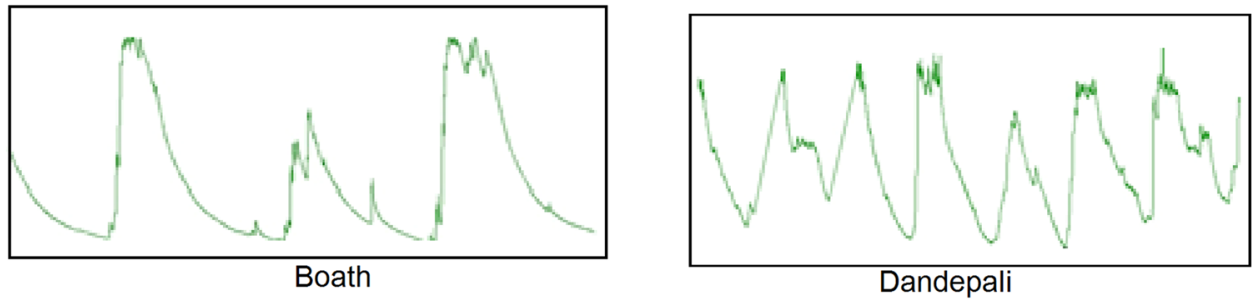

Flat top Crest

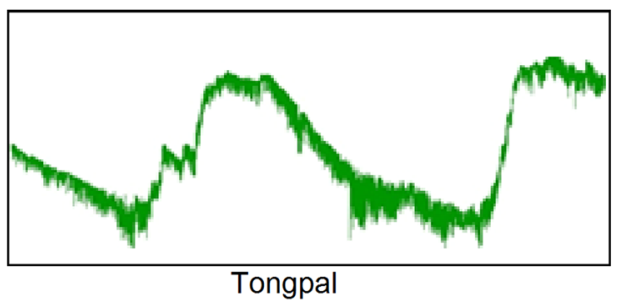

Rounded Crest

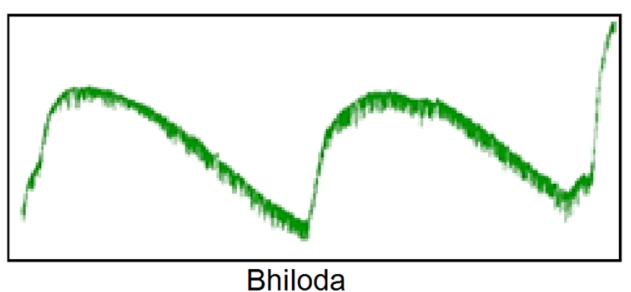

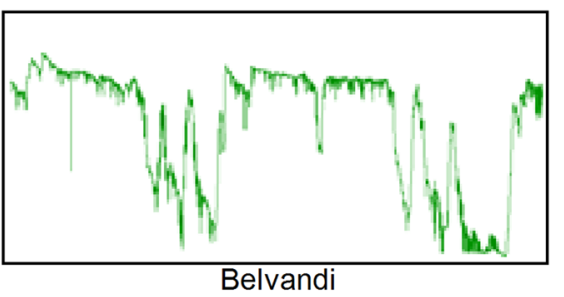

Belvandi

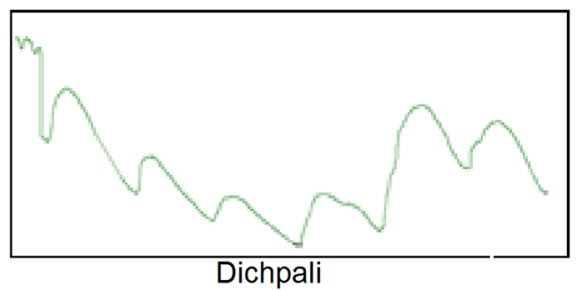

recession limbs. Also, they generally don't show any break in slope trend throughout the limb (Fig. 5).

2. U type curves are those curves where rising limb has a nearly uniform slope, but the recession limb shows a definite break in the slope. The initial discharge is gentle followed by a fast phase of discharge and then again a slowdown giving rise to $U$ shaped curve. Sometimes the slope is initially steep and subsequently gentle after some period of discharge and a combination of $\mathrm{U}$ and $\mathrm{V}$ type is developed. The lowest part of the trough is not very sharp in angle, rather it is nearly flat or curved (Fig. 6).

3. S type curves are those, which have sharp initial and ultimate-slope of recession limb and in between flat or very gentle slope giving rise to two breaks in the actual slope of the recession limb. The $\mathrm{S}$ type curves indicate low seasonal fluctuation and are not very common, e.g. Sarangarh (Fig. 7).

The significance of the hydrograph shape is in the interpretation of aquifer characteristics and stress. The $\mathrm{V}$ type curve indicates quick dissipation, $U$ type indicate initial quick adjustment and then slow dissemination whereas the $\mathrm{S}$ type curves are indicative of poor response of the aquifer. The $\mathrm{U}$ shape indicates comparatively best sustain diffusivity of the aquifer. The order of abundance found in these shapes in the Peninsular hard rock is $\mathrm{V}>\mathrm{U}>\mathrm{S}$.

\section{Scheduled measurements}

The historical groundwater monitoring programmes in India, though quite extensive and commendable in many ways, have been wanting in several respects. The seasonal fluctuation in groundwater level so obtained is used in resource estimation adopting the groundwater level fluctuation method. These traditional measurements of groundwater level on predetermined fixed dates (these times are rather arbitrarily selected during pre-monsoon, monsoon, post-monsoon and winter seasons) has limitation in knowing accurate seasonal fluctuation (thus recharge estimation by water balance of the unconfined aquifer gets uncertain in many ways). The hydrograph of DWLR data can provide more realistic measurements, as can be seen by the study of a true hydrograph, generated by the DWLR. For instance, in Chhattisgarh traditionally pre and post monsoon measurement of water levels of hydrograph stations is carried out between 20th and 30th May and from 1st to 10th November respectively. Study of true hydrograph (Fig. 8) shows the lowest water level may shift as per the monsoon every year, so fixed date may not give the lowest water level. Similarly for measuring seasonal fluctuation, so far November data is considered, instead of August data, to allow the aquifer to readjust the water level after the heavy monsoon 

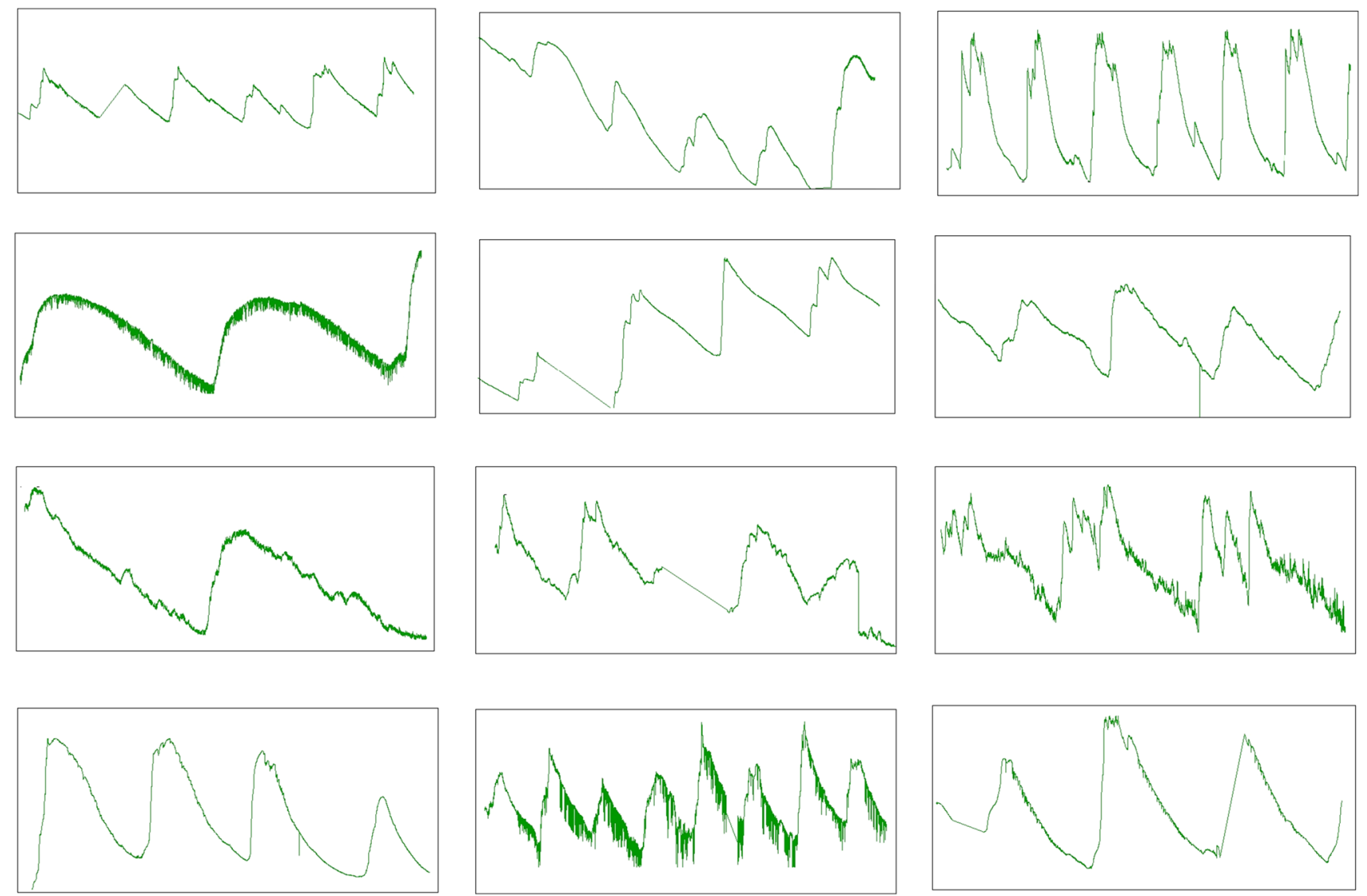

Fig. 5 V-type curve. Note the trough shape and angle of recession limb to rising limb
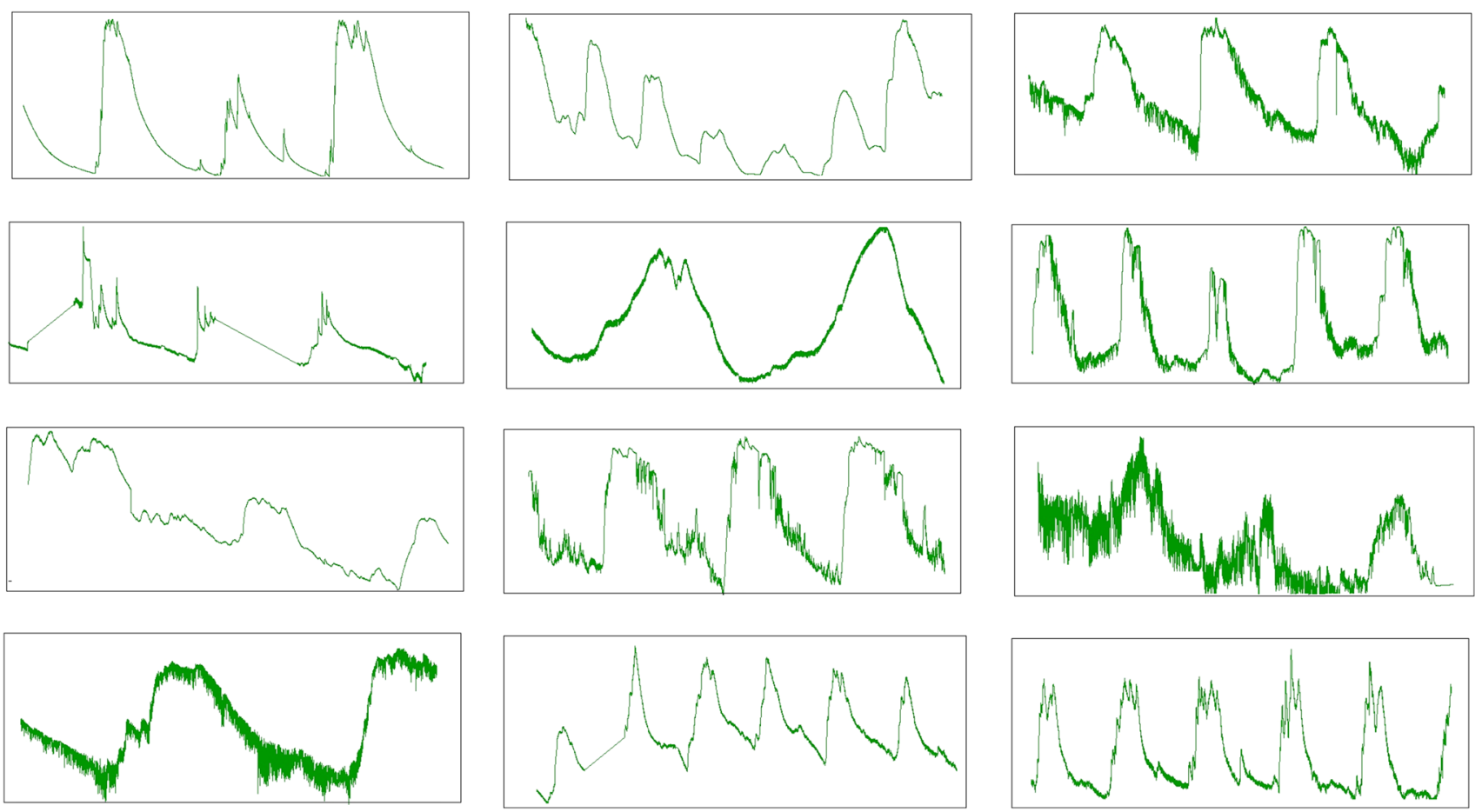

Fig. 6 U-type curve. Note the trough shape and angle of recession limb to rising limb 
Fig. 7 S-type curve. Note the smooth and simplified curve outside of each graph for the shape of recession limb
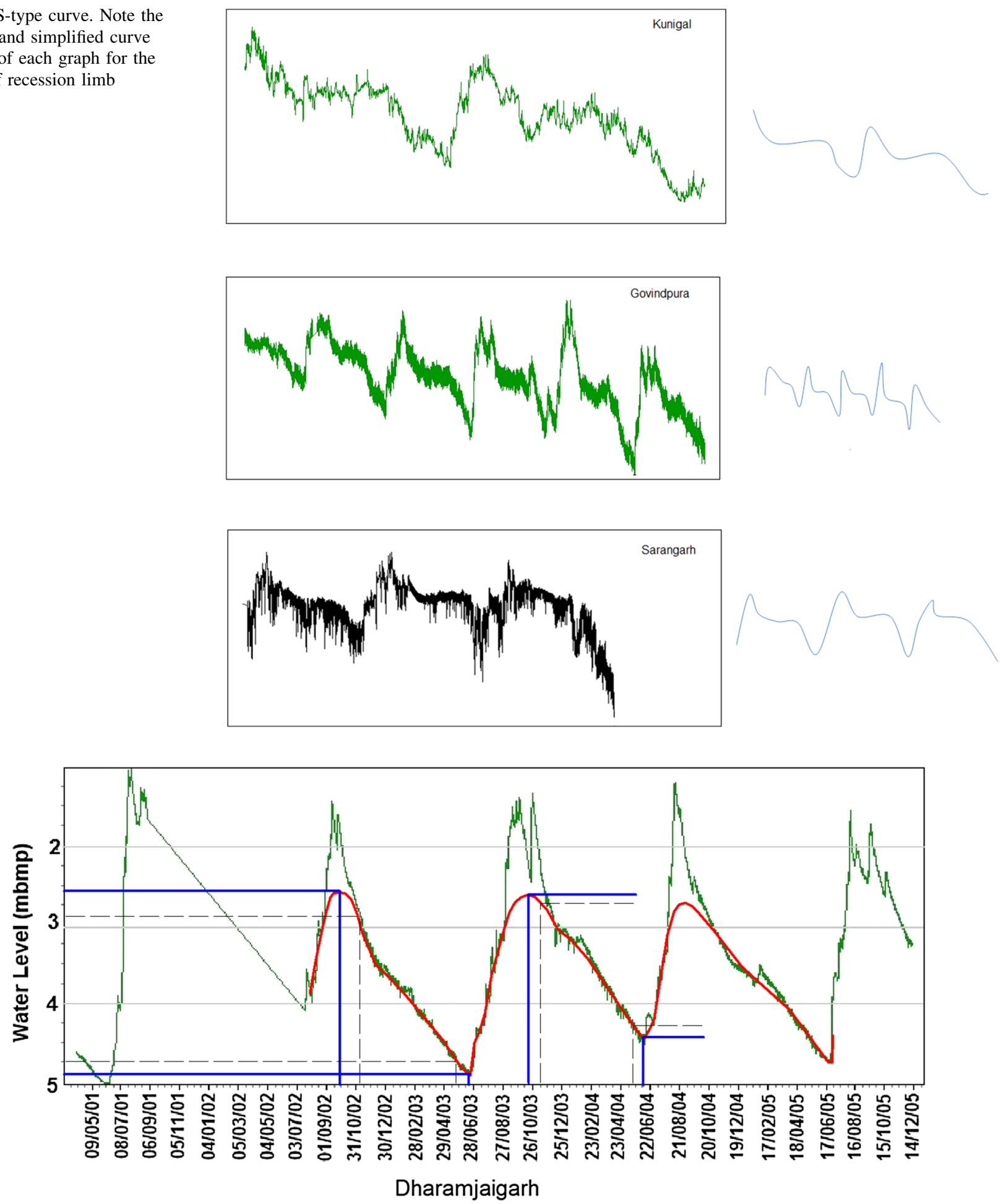

Fig. 8 Hydrograph showing true seasonal fluctuation. Note the difference between water level of scheduled measurement (broken line) and actual fluctuation recorded (blue solid line)

precipitation. The figure shows that the very objective of taking November data instead of August has not been fulfilled at least for the given year. The hydrograph generated by DWLR data provide flexibility in choosing the accurate pre and post monsoon dates and thus provide the actual/correct seasonal fluctuation, which ultimately can produce a more rational and credible groundwater resource estimation. It is observed in many cases that by 


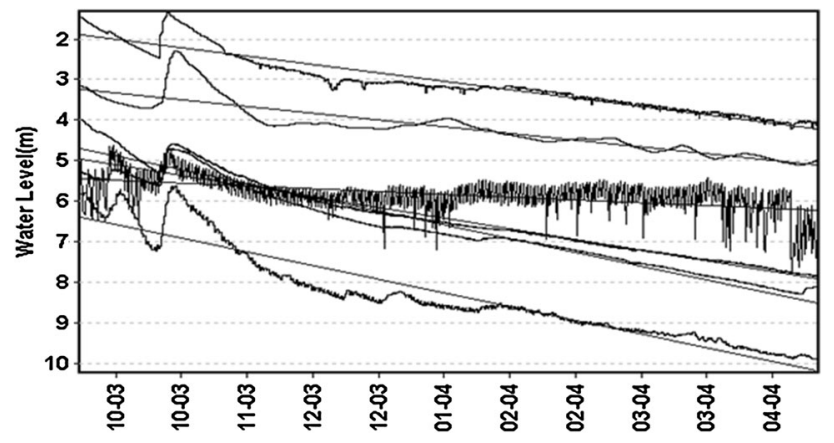

Fig. 9 Hydrographs of multiple wells in Raigarh district, Chhattisgarh State. Note the rise in level at end of January

10th November considerable loss of the resource by means of draft or base flow takes place and this drawback can also be overcome with the help of DWLR data generated true hydrograph (Fig. 8).

Similarly, for optimal identification of the specific yield it is necessary to carry out the water balance study of the highest (peak) to the lowest (trough) water table. Thus, identification of the peaks and troughs and their times of occurrence are important. Further, the stress on aquifer can also be observed through true hydrograph. The recession curve shows minor rise just after "Rabi" crop session (end of January), which is an indicative of the release of stress of aquifer due to stop of withdrawal from aquifer or nonpumping of groundwater. This can be seen in successive years and large number of wells in a groundwater irrigated area like Raigarh district of Chhattisgarh (Fig. 9).

\section{Line patterns of true hydrograph}

The true hydrograph having a fixed scale can be used to predict the nature of aquifer based on its apparent line thickness. When annual cycle of true hydrograph due to the scale of potting of time series data produced a compact form and the minute fluctuations in groundwater levels plotted close together, this provides an apparent line thickness and can be visually compared as thin or thick apparent line (Figs. 5, 6, 7). The minute fluctuations of groundwater levels may be caused due to various factors like frequent change in saturation level or in pressure head within aquifer. The detail of this is discussed in the subsequent paragraphs.

\section{Discussion}

Recharge has been defined as "the entry into the saturated zone of water made available at the water-table surface, together with the associated flow away from the water table within the saturated zone" (Freeze and Cherry 1979). The manner in which infiltrating water is transmitted through the system controls system response to recharge. If the rate of recharge were constant and equal to the rate of drainage away from the water table, water levels would not change. For unconfined aquifers, a time lag occurs during which the pressure change in the land surface is propagated through the unsaturated zone to the water table. Air must move through the unsaturated zone to transmit a pressure change. Therefore, an imbalance exists between the pressure on the water in the well and the water in the aquifer until the pressure front arrives at the water table. This imbalance produces a change in the observed water level in the well. Weeks (1979) and Rojstaczer (1988) present in-depth analyses of this phenomenon. The length of the time lag increases with increasing depth to the water table and with decreasing vertical air diffusivity of the unsaturated zone sediments. The barometric efficiency of an unconfined aquifer is not constant, because these two factors can change over time. Techniques for identifying and removing the effects of atmospheric-pressure changes from observed water levels are described in Weeks (1979) and Rasmussen and Crawford (1997). Pressure transducers are often used to monitor water levels; these devices can be affected by atmospheric pressure changes. Non-vented or absolute, transducer readings may reflect atmospheric-pressure changes and could give the false impression that waterlevel fluctuations are much greater in magnitude than they are in reality. However, all the above-discussed deviations are not significant in the context of the present paper. Well hydrographs have been classified earlier based on its segment slope and are used to compute recharge, specific storage and time lag (Raj 2004). The shape of crest and trough and therefore the shape of the annual cycle is the product of aquifer character, recharge and discharge quantum and its pattern and have been utilized in this study as a tool to arrive in for genetic classification of hard rock aquifer (see the supplementary sheets-1 \& 2).

Identification and interpretation of a particular shape of curve is significant in this process. The pointed crest reflects immediate diffusion of water, whereas flat top and rounded crest indicates delayed and slow diffusivity respectively.

The vertical connectivity of aquifer (or hydraulic continuity) at any place and its nature can be judged by putting more than one piezometer at that place. The comparisons of shape of true hydrograph generated by shallow and deeper aquifers (Fig. 10) reflected nearly similar pattern for Bapulapadu and Udaipur, hence considered as a single aquifer, however the graph generated for Wadrafnagar and Mahasamund shows different behavior indicating different aquifers. The effect of pumping is more clearly seen in shallow aquifer at Wadrafnagar, however the magnitude of pumping effect 
SHALLOW
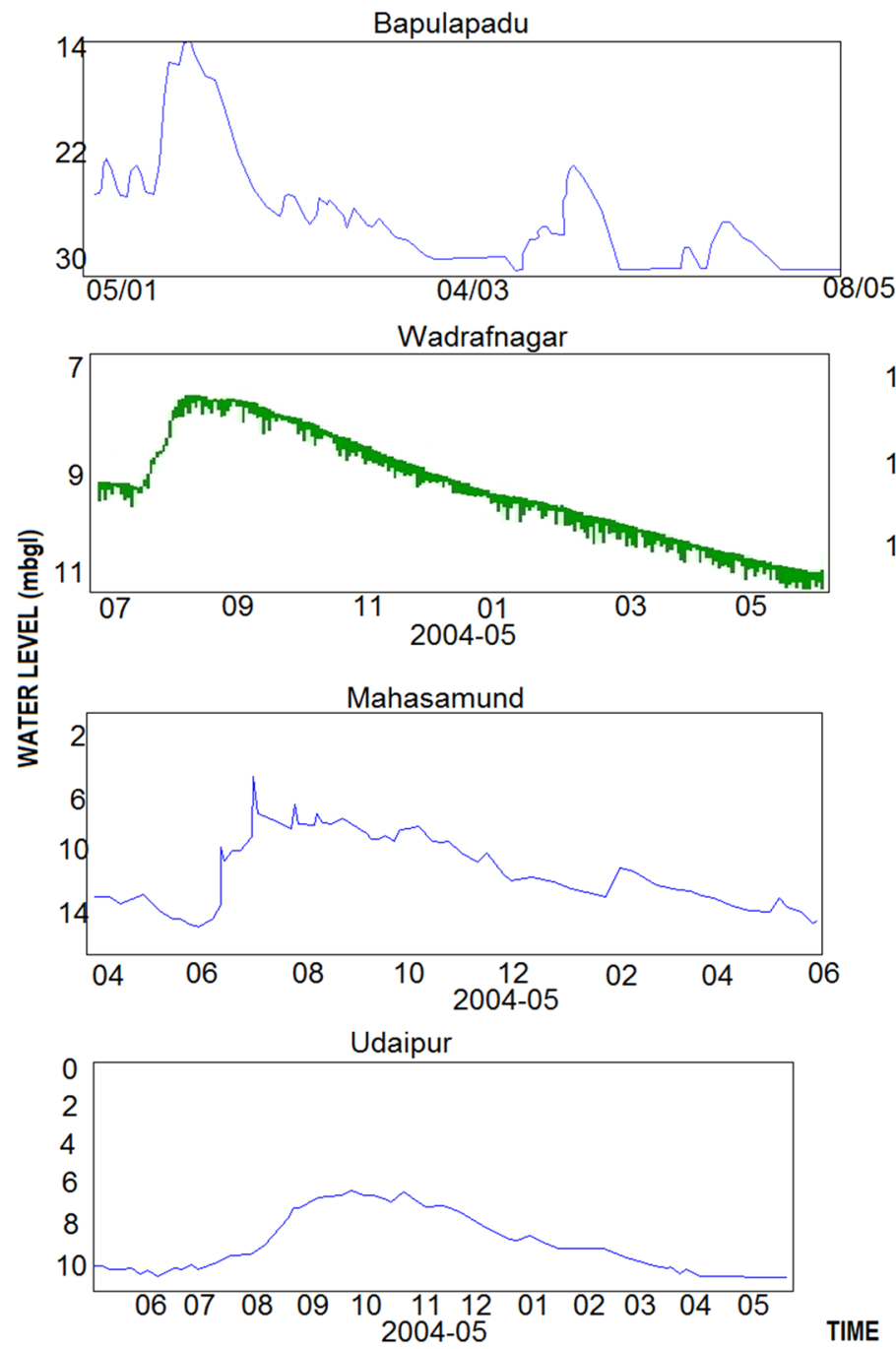

DEEPER
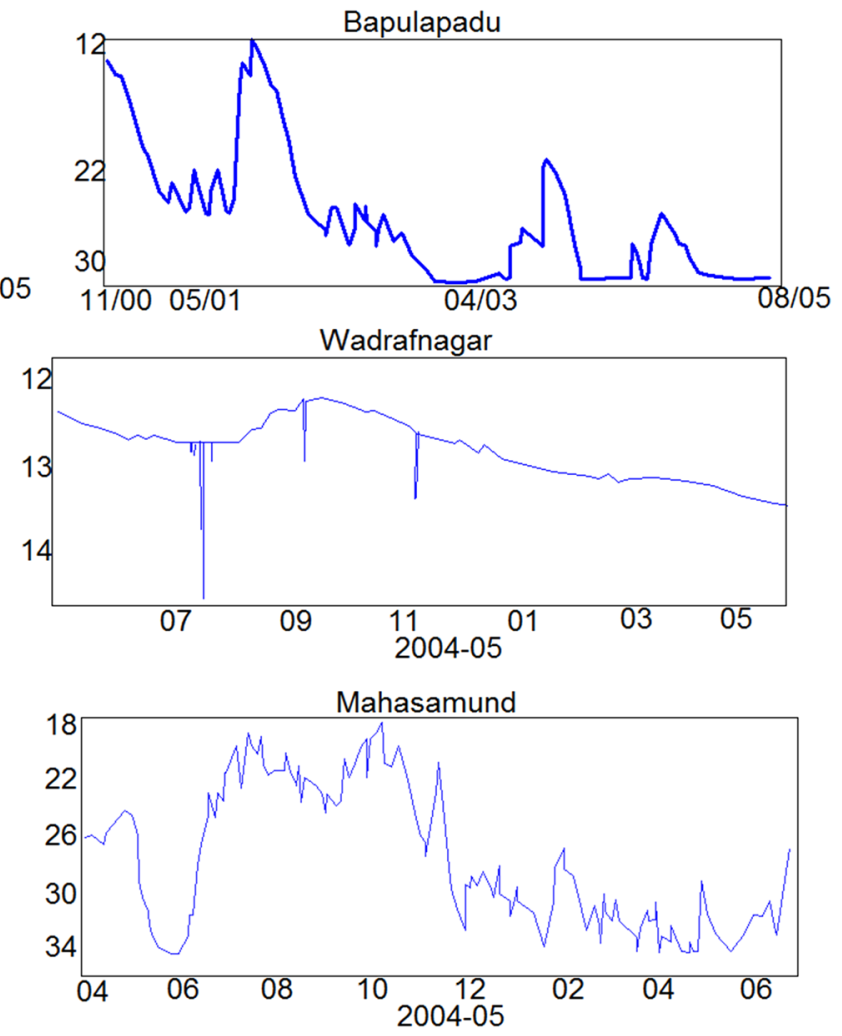

Udaipur

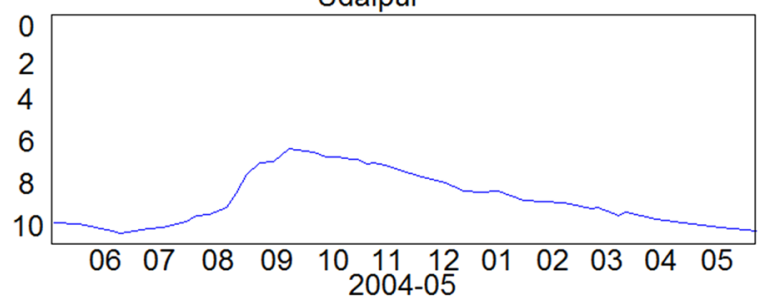

Fig. 10 Comparison of hydrographs generated of shallow and deep wells of same location for same period

is high in the deep zone which is semi confined. Similarly the effects of recharge/discharge events are much higher in magnitude on the confined aquifer of Mahasamund (Fig. 10) compared to the shallow unconfined aquifer (see the supplementary sheets-1 \& 2).

Effects of pumping in nearby area can be observed in many of the hydrographs. However a small amount of pumping does not affect the overall shape of recession curve. Thus, comparison of curves, so generated in a constant scale format for any region, can eventually be compared the aquifer character and can be used for classification of aquifers. Phreatic, semi-confined or confined aquifer may show different response for recharge or discharge event based on aquifer character or its position. Further, comparison of any two or more phreatic/semiconfined or confined aquifer is possible based on true hydrograph patterns. The magnitude of fluctuation depends on the quantum of recharge or discharge event and aquifer character.

In Peninsular India, all the hard rock true hydrographs show a predominant annual cycle in response to the wet and dry season. With the onset of monsoon, throughout the monsoon the curve form rising limb and once the monsoon retrieve the curve starts forming recession limb, which continue until the next monsoon (annual cycle). Successive annual cycles join together to form long-term hydrograph. With the full knowledge of fluctuation of groundwater level, the hydraulic conductivity/filtration conditions can be calculated by analyzing recession curve of well hydrograph (Ferdowsian et al. 2001; Gailuma and Vitola 2009; Posavec et al. 2006; Sujono et al. 2004). The rapid decline in recession curve corresponds to better filtration conditions (Gailuma and Vitola 2009). Therefore, it can be stated comparatively that the $\mathrm{U}$ shape curves correspond to better 

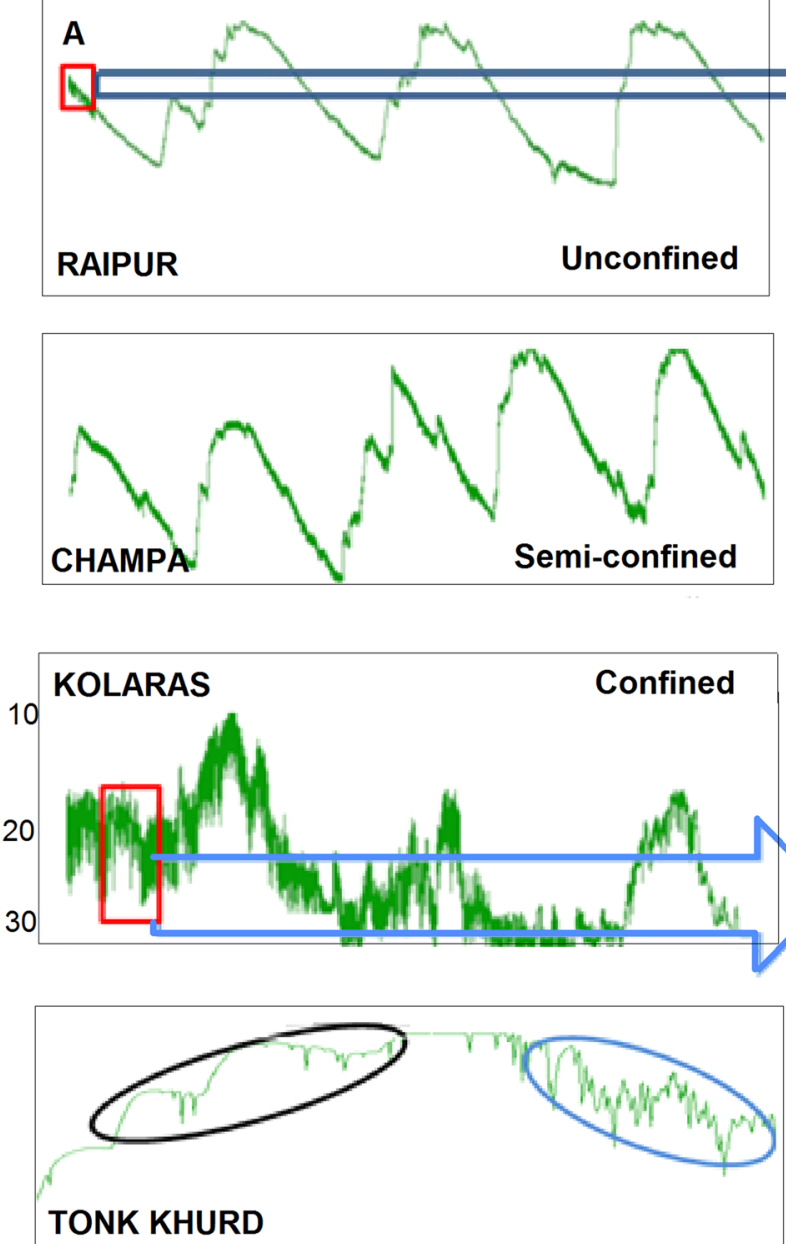

Fig. 11 Pattern of water level fluctuation produced due to pumping and confining condition causes apparent line thickness. Note the gradually increasing apparent line thickness with semi-confined and confined condition. The zoom in view of thick line due to pumping at

hydraulic conductivity $(k)$ than the V shape, whereas the $\mathrm{S}$ shape curves represents the lowest hydraulic conductivity of the aquifer. So, based on hydraulic conductivity (k) aquifers can be classified as $\mathrm{U}>\mathrm{V}>\mathrm{S}$ type curve. In the Peninsular hard rock $\mathrm{V}$ type is more abundant over $\mathrm{U}$ type, while $\mathrm{S}$ type is the least abundant type since it largely corresponds to aquicludes.

It has also been observed that the curve types are independent of lithology of the aquifer. Litho-type curve shape correlation indicates both $\mathrm{U}$ and $\mathrm{V}$ type curve is found in granite, basalt and limestone aquifer (Figs. 5, 6), whereas all granite or basalts do not form any specific type of curve (See the supplementary sheets-1 \& 2). Therefore, similarity in porosity and permeability pattern within different litho-unit is responsible for the broad similarity of curve shape.

Further, the apparent line thickness of the curve (on a fixed scale) in the long-term true hydrographs can be
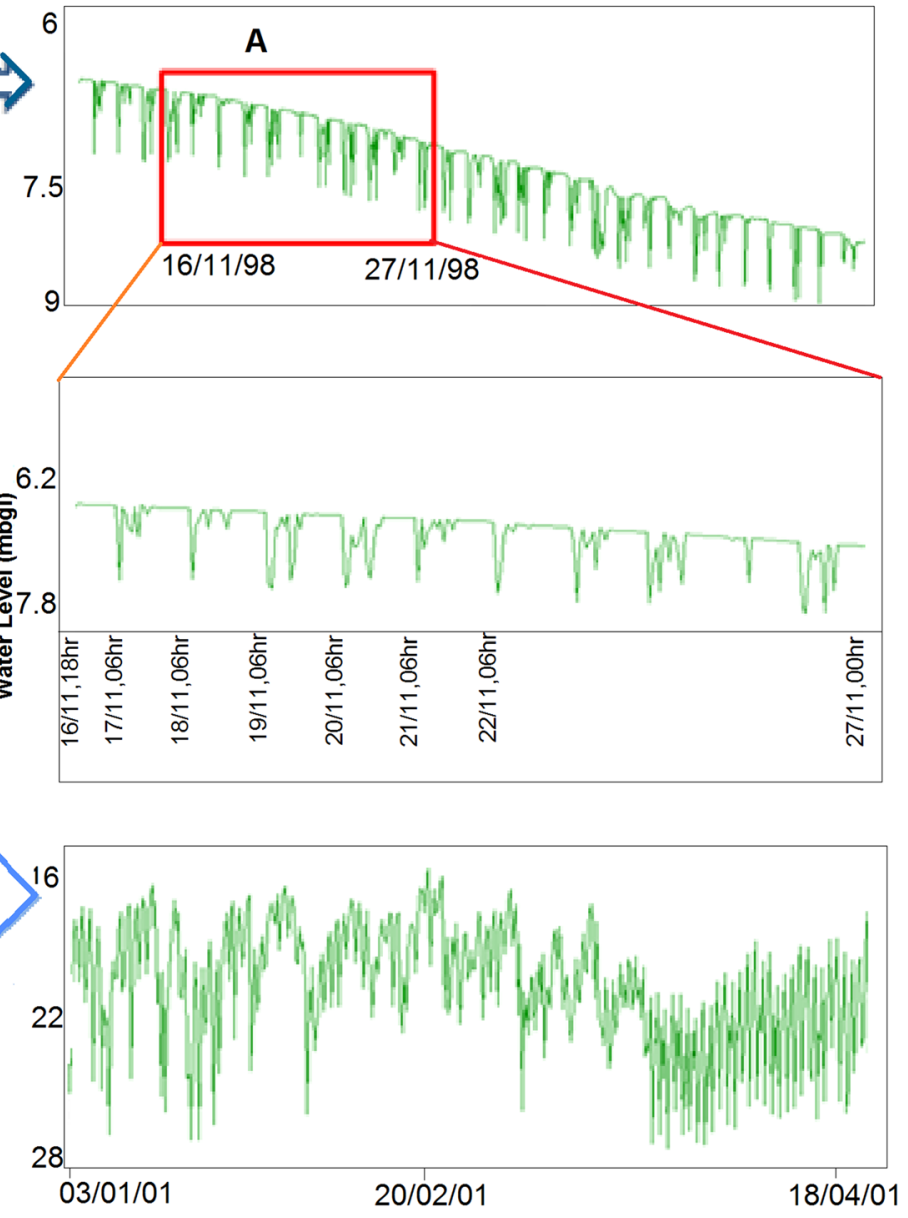

box $A$ (also at black ellipse, Tonk khurd) when further blown up reveals top smooth drop in water level. Kolaras $(S)$ curve produces thicker apparent line due to fluctuation in confined condition and shows irregular pattern in zoom in view, also see the blue ellipse

compared to characterize the aquifer response. The apparent line thickness of the curve can be thin or thick due to the presence of minute fluctuations (Fig. 11). The apparent thin line corresponds to unconfined aquifer. The apparent thick lines can be produced by two different reasons. Naturally produced apparent thick lines are due to irregular minute fluctuations occurring frequently due to change of pressure head/piezometric level in semi-confined to confined aquifers. However, the apparent thick lines can also produce due to periodic pumping in and around the piezometer during the period of measurement. The minute fluctuation produced due to changes in piezometric head or due to the effect of pumping have different pattern and can be distinguished easily. When the small part (of a small period) of an apparent thick line plot is enlarged substantially it can be seen that the effect of pumping produce top smooth line and drop in level from that lines whereas the naturally produced fluctuations are irregular in size and 
arrangement (Fig. 11). The unconfined aquifers produce thin lines because change in water level of unconfined aquifer requires a change in saturation level within the aquifer, which does not occur so frequently as change of pressure head of confined conditions. It has been observed, more the confined condition more is the minute fluctuations, thus thicker the apparent line. Fluctuation produced due to regular pumping have a smooth top since in general the duration of pumping of a well remains comparatively smaller than non-pumping. The non-pumping period produce rather smooth line and pumping produce fall in level from that smooth line surface. This produces a typical pattern, which differs significantly from the natural fluctuation caused due to change of pressure head (also see the supplementary sheets-1 \& 2).

\section{Implication of automated genetic classification}

1. Once the value of aquifer parameters for aquifer classes in an area is fixed, these can be used for various computations of resource and prediction for its availability.

2. Managed aquifer recharge can be planned based on the class of the aquifer.

3. Water use efficiency can be improved upon based on the class of aquifer for food and water security.

\section{Conclusion}

The aquifer response to recharge-discharge phenomenon of hard rock aquifers has been investigated by analyzing over 250 well hydrographs, collected from eight States of Peninsular India. The true hydrographs are based on continuous (six hourly) time series data recorded with the help of digital automatic water level recorders fitted in purposebuilt piezometers. Due to the high heterogeneity of hard rock aquifers each well/piezometer produces a hydrograph that is unique and does not match with hydrographs of other wells. However, the successive annual curves of the hydrograph of a well remain nearly similar in shape though the magnitude of fluctuation varies based on the quantum of recharge-discharge and its pattern. This clearly reflects that the shape of the hydrograph is controlled by aquifer characteristic and its response and does not entirely depend on recharge-discharge quantum and pattern. The combination of rising and recession limbs produces different crest and trough shapes. Similarity in crest and trough shape represents similarity in aquifer characteristics. As found during this research shapes of the crests and troughs of the true hydrographs can form a basis for devising a genetic classification of the aquifers. Three crest types namely 'point', 'rounded' and 'flat top' crest and three trough types viz. $\mathrm{V}$ shape, $\mathrm{U}$ shape and $\mathrm{S}$ shape have been identified in hard rocks of Peninsular India. The V type curve indicates quick dissipation; $\mathrm{U}$ type indicates initial quick adjustment and then slow dissemination whereas the $\mathrm{S}$ type curves are indicative of poor response of the aquifer. The U shape indicates relatively better sustained diffusivity of the aquifers. Confined and unconfined aquifers can be differentiated based on the apparent line thickness. Thin line denotes unconfined and thick line denotes confined aquifer. Intermittent apparent thickness of line corresponds to semi-confined aquifer. Fluctuation produced by pumping of well can be segregated based on the fluctuation pattern.

The identified patterns in the hydrographs provide newer insights into the response of hard rock aquifers to recharge-discharge phenomenon. Types of aquifers and their behaviors can be derived from the patterns in the hydrographs. Relative potential of the aquifers can also be assessed from the patterns in the hydrographs. Analysis of available true hydrographs in association with other related data can help in planning groundwater management interventions in hard rock areas.

The proposed aquifer classification has great potential for applied use; several potential lines of research exist that could further the usefulness of the method.

Acknowledgments The authors are grateful to Sh. Sushil Gupta, Chairman, CGWB for allowing us to publish the paper and for providing the logistical support during the study. Fruitful discussions with our colleague Sh. S. K. Sinha have been beneficial in finalization of this paper. Sincere thanks are due to Sh. H. K. Sahu, Member Secretary, Upper Yamuna River Board for his encouragement. The paper has been benefited by review comments of an anonymous reviewer and the able editorial handling and suggestions of Dr. Abdulrahman I. Alabdulaaly. The views expressed in the paper are the authors own and not of the department to which they belong.

Open Access This article is distributed under the terms of the Creative Commons Attribution 4.0 International License (http:// creativecommons.org/licenses/by/4.0/), which permits unrestricted use, distribution, and reproduction in any medium, provided you give appropriate credit to the original author(s) and the source, provide a link to the Creative Commons license, and indicate if changes were made.

\section{References}

Ferdowsian R, Pannell DJ, McCarron C, Ryder AT, Crossing L (2001) Explaining groundwater hydrographs: separating atypical rainfall events from time trends. AJSR 39(4):861-875. http:// www.general.uwa.edu.au/u/dpannell/dpap0012.htm

Freeze RA, Cherry JA (1979) Ground water. Prentice-Hall, Englewood Cliffs

Gailuma A, Vitola I (2009) Recession curve analysis approach for groundwater. www.puma.lu.lv/fileadmin

Hydrology Project (2000) Understanding conventional and DWLR assisted water level monitoring, training modules \#1 to 5 by

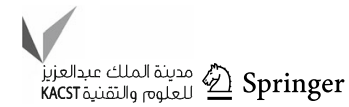


DHV consultants BV \& DELFT Hydraulics with Halcrow Tahal, CES, ORG and JPS. pp 1-68. (http://www.cwc.gov.in/main/HP/ download/DWLR)

Kumar CP (2010) Groundwater data requirement and analysis. http:// www.acadamea.edu

Maréchal JC, Sarma MP, Ahmed S, Lachassagne P (2010) Establishment of earth tides effect on water level fluctuations in an unconfined hard rock aquifer using spectral analysis. http://arxiv. org/pdf/1002.3916

Posavec K, Bacani A, Nakic Z (2006) A visual basic spreadsheet macro for recession curve analysis. Ground water 44(5):764-767

Raj P (2004) Classification and interpretation of piezometer well hydrographs in parts of southeaster peninsular India. Environ Geol 46:808-819

Rasmussen TC, Crawford LA (1997) Identifying and removing barometric pressure effects in confined and unconfined aquifers. Ground Water 35(3):502-511
Rojstaczer S (1988) Determination of fluid flow properties of the response of water level in well to atmospheric loading. Water Resour Res 24(11):1927-1938

Singhal BBS (2007) Nature of hard rock aquifers: hydrogeological uncertainties and ambiguities. Groundwater dynamics in hard rock aquifers. Capital Publishing Company, New Delhi

Sujono J, Shikasho S, Hiramatsu K (2004) A comparison of techniques for hydrograph recession analysis. Hydrol Process 18:403-413

Thakur GS, Thomas T (2011) Analysis of groundwater levels for detection of trend in Sagar district, Madhya Pradesh. J Geol Soc India 77:303-308

Weeks EP (1979) Barometric fluctuations in wells tapping deep unconfined aquifers. Water Resour Res 15(5):1167-1176 